http://dx.doi.org/10.1590/0103-166X2014000200001

\title{
Internacionalização da investigação e do ensino em Psicologia e Educação: demandas Portugal-Brasil
}

\author{
Internationalization of teaching and research \\ in Psychology and Education: \\ Portugal-Brazil demands
}

Feliciano Henriques VEIGA ${ }^{1}$

\begin{abstract}
Resumo
A problemática da internacionalização da investigação e do ensino tem surgido como importante e atual em várias áreas e diferentes modelos teóricos; destaca-se, no entanto, a escassez de investigações e a necessidade de aprofundamento das existentes. O objetivo geral desta conferência foi considerar especificidades da internacionalização da investigação e do ensino em Psicologia e Educação, centradas, sobretudo, na relação Brasil-Portugal. Falar da dimensão transnacional da investigação e do ensino implicou considerar variáveis como educação e valores, humanização, democratização, fragilidades, investimentos, espaços de conhecimento, visibilidade, avaliação, projetos e acordos bilaterais. O problema de pesquisa foi o seguinte: Como se processam as relações entre essas variáveis a fim de que sejam atendidas as múltiplas interações que as condicionam e de que sejam levantados desafios globais e buscas de interação Brasil-Portugal? O conceito de internacionalização da educação superior surge com uma diversidade de termos relacionados e várias fases de desenvolvimento. A internacionalização foi conceitualizada como trocas internacionais relacionadas com a educação, e a globalização foi entendida como uma fase avançada do processo de internacionalização. Constatou-se a falta de estudos empíricos, embora se encontrem perspectivas conceituais que deixam antever hipóteses de respostas aos problemas de afirmação da Psicologia e da Educação, nos desafios derivados da internacionalização da investigação e do ensino em geral, e no espaço de conhecimento luso-americano. Pôde constatar-se que, ao longo da história, o maior erro da educação e da ciência foi "dar ajuda ao mais potente" na guerra e na fome. Conclui-se que urge humanizar a ciência e, internacionalizando-a, levá-la aos cidadãos, qualquer que seja o país onde se encontrem. Implicações sociopolíticas são referenciadas, bem como sugestões de intervenção, rumo a uma educação para todos.
\end{abstract}

Palavras-chave: Educação; Ensino superior; Estudantes estrangeiros; Psicologia.

$\checkmark \nabla v$

1 Instituto de Educação, Universidade de Lisboa, Área de História e Psicologia da Educação. Alameda da Universidade, 1649-013, Lisboa, Portugal.E-mail: <fhveiga@ie.ul.pt>.

Artigo baseado na Confêrencia proferida na Pontifícia Universidade Católica de Campinas, na Aula Inaugural do Programa de Pós-Graduação em Psicologia, em 12 de fevereiro de 2014.

Apoio: Fundação para a Ciência e a Tecnologia e Instituto de Educação da Universidade de Lisboa. 


\begin{abstract}
The issue of internationalization of research and teaching has arisen of teaching and research internationalization as important and current in different domains and theoretical models, despite the lack of studies and the necessity of deepening the existing ones. The main purpose of this conference was to consider some specificities of teaching and research internalization in psychology and education, teaching and research focusing on the relationship between Portugal and Brazil. To address the transactional dimension of teaching and research implied considering variables such as education and values, humanization, democratization, fragilities, investments, knowledge environments, visibility, assessment, projects and bilateral agreements. The problem considered was: how do relationships between these variables occur, considering the multiple interactions that constrain them, the global challenges, and the search for Portugal-Brazil interactions? The concept of higher education internationalization has emerged encompassing a diversity of related notions and several development phases. Internationalization was conceptualized as international exchanges related to education, while globalization was understood as an advanced phase of the internationalization process. The lack of empirical studies was observed, although some conceptual perspectives suggest hypothesis to address psychology and education affirmation difficulties, when responding to the challenges posed by teaching and research internationalization, both in general and in the Luso-American knowledge sphere. It can be seen that, throughout history, the greatest mistake in education and science was "giving help to the most powerful", in war and in starvation. We conclude by mentioning the urgency to humanize science, internationalizing and presenting it to the citizens, whatever their country. Sociopolitical implications are mentioned, and intervention suggestions are made, directed towards an education for all.
\end{abstract}

Keywords: Education; Higher Education; Foreign students; Psychology.

O estudo e a revisão do tema consideraram como referenciais autores com vários tipos de vozes, salientando-se três dimensões deste trabalho: Introdução Brasil-Portugal e Educação e Valores; Tema específico Ensino, Investigação e Internacionalização, e um núcleo de Ideias finais.

Brasil e Portugal sempre viveram como irmãos e parecem estar hoje num novo ciclo, olhando para a configuração das suas políticas educativas. Partilham itens de uma agenda transnacional, como escolarização de amplas camadas sociais e valorização de aprendizagens extraescolares; implementação de mediações educativas; e elaboração de rankings de escolas.

No Brasil, realçam-se orientações gerais, ainda com aparentes impregnações liberais; em Portugal, passa-se, em brusca transição, para um Estado cada vez mais minimizado. No Brasil, questiona-se, por vezes ardentemente, a qualidade do progresso em curso, bem como as desigualdades inerentes a um processo rápido e volumoso; em Portugal, parece acentuar-se a quebra da crença na escolaridade, o aumento da precarização da profissão docente, a fuga de cérebros e a emigração qualificada.

No recente livro de Moreira (2013), intitulado bússola", o professor, falando de um mundo sem norte, refere-se a um globalismo à deriva, que leva ao recuo dos direitos humanos. Explica a desorientação de órgãos internacionais, como a própria Organização das Nações Unidas, que atuam sem "conceito de coordenação estratégica" e fecham os olhos ao liberalismo e ao economicismo, que, destruindo o estado social, corrói a confiança entre as sociedades. Fala da "troca do valor das coisas pelo preço das coisas" (Nóvoa, 2014, p.16), adverte que "só há futuro se respeitarmos o eixo da roda que são as pessoas e os valores" (p.68) e apela à "vigilância ativa do humanismo" (p.378). Falar de Brasil-Portugal implica considerar variáveis importantes, que aqui ficam limitadas a duas: "educação e valores".

\section{Educação e valores}

Num estudo de 2014, intitulado "Literacia Social: os valores como Fundamento de Competência", da Universidade Católica Portuguesa e do Instituto Luso para o Desenvolvimento Humano, os indivíduos com mais habilitações escolares e com mais rendimentos econômicos foram os que deram menos importância à solidariedade, à justiça e aos valores democráticos. Quanto mais avançamos nos 
níveis de instrução, do $1^{\circ}$ ciclo ao ensino superior, a importância da justiça ou da solidariedade vai baixando progressivamente. Os mais instruídos e os mais ricos são aqueles que mais desvalorizam a justiça e a solidariedade. Quando questionados sobre a importância de ajudar os outros, $87 \%$ dos inquiridos com o $1^{\circ}$ ciclo respondem afirmativamente; essa percentagem baixa para $83 \%$ quando os inquiridos têm o $2^{\circ}$ ciclo; para $74 \%$ quando têm o $3^{\circ}$ ciclo; para $59 \%$ quando têm bacharelado; e ficando o valor mais baixo na fatia dos licenciados, mestres ou doutorados, com 53\%. A mesma pergunta cruzada com os níveis de rendimento revela que $86 \%$ dos inquiridos que ganham até 500 euros consideram muito importante ajudar os outros; essa percentagem decresce à medida que os rendimentos aumentam, chegando a $47 \%$ com o grupo dos que ganham mais de quatro mil euros por mês.

A explicação passa pelo fato de os elevados rendimentos e os elevados níveis de instrução "serem contrários" àquilo que é a harmonia social e o desenvolvimento pessoal, o que revela que é preciso mudar o sentido da educação, a dimensão humana, que está cada vez mais afastada dos currículos.

Diante do exposto, o que se pode pensar do que tem sido e do que quer ser o ensino e a investigação, na sua dimensão de internacionalização? É o que se passa a considerar a seguir.

\section{Ensino, investigação e internacionalização}

\section{Ensino}

Desde a década de 1980, Portugal aumentou de forma exponencial a oferta formativa e o número de diplomados. De acordo com o relatório Education at a Glance (Organisation for Economic Co-Operation and Development, 2013), a taxa de graduação em licenciatura cresceu de 15\% em 1995 para 40\% em 2011, o que coloca Portugal na média dos países da Organização para a Cooperação e Desenvolvimento Econômico (OCDE) (39\%). $O$ ensino dito superior democratizou-se e chegou a largas classes sociais, assumindo-se como o principal fator de ascensão social. Temos, hoje, licenciados, mestres e doutores que são fruto do seu esforço e trabalho, mas cujo acesso ao ensino superior apenas foi possível graças à Ação Social Escolar.

Hoje, entretanto, 33\% dos alunos inscritos no ensino superior não chegam a concluir o grau. O fenômeno do abandono escolar merece a atenção das Universidades e dos Governos: parece que a situação não é muito diferente no Brasil.

A par do ensino, também a investigação em Psicologia e Educação deve contribuir para a construção de um futuro mais humano e social, que busque novas respostas para "problemas de pesquisa" que sejam pertinentes em Portugal e no Brasil.

\section{Investigação}

O que é e o que tem sido a investigação? A investigação é o que a ciência faz na procura da verdade. O primeiro reitor da Universidade de Brasília, Darcy Ribeiro, escreveu que "podemos não ter nenhuma verdade a dar, a não ser a única verdade possível, que é a de buscá-la eternamente" (Nóvoa, 2014). Essa é uma bela referência que me transporta ao poema seguinte:

\section{Reparto-me eu por várias teorias / e vou de uma / a outra / como um pássaro difuso nos ramos / de uma palmeira / umas / dão-me alegrias / contidas / outros melancolias / que choram / assim / meus planos e sonhos / se repartem pelos dias / porém, / quando vejo a ciência de mão dada com o bem / a minha alma ganha uma paz rara / e tamanha (Veiga, 2006, p.44).}

Descendo à prosa, vê-se que, se a investigação é grande na sua importância, seus problemas não são menores. Temos uma investigação ainda muito acadêmica, que se destina em grande parte à obtenção de graus universitários ou à preparação de provas de progressão na carreira docente (Pacheco, 2010). A investigação que temos, muitas vezes, não toma como ponto de partida os problemas detectados no mundo, no campus da Psicologia e Educação, nem os seus resultados pare- 
cem relevantes para a atuação dos profissionais e dos decisores políticos. A Psicologia e a Educação revelam muitas limitações, mais evidentes se discutirmos a sua cientificidade, como fazem Estrela (2008) e Nóvoa (2001) ao levantarem as fragilidades das Ciências da Educação.

Na derivação de uma ideia de George Shaw, prêmio Nobel de Literatura em 1925, tem-se gasto muito tempo a descrever as coisas como elas são e a dizer "por quê" quando o que é preciso é sonhar com coisas que não existem e perguntar "por que não". Temos, nos dias de hoje, uma investigação produtivista, muito voltada para o número de publicações em revistas indexadas ao sistema Intitute for Scientific Information (ISI) ou ao Scopus, muitas vezes sem se preocupar com problemas socialmente úteis nem com temáticas fundamentais para a realidade psicoeducacional.

A visibilidade da comunidade científica passa pela sua capacidade de interrogação do real e pelo diálogo que for capaz de travar, inclusive com o poder político. Nesse caso, apenas estando organizada pode uma determinada comunidade acadêmica pensar-se criticamente, refletir sobre seu trabalho, identificar obstáculos, superar fragilidades e elevar os níveis de exigência (Lima, 2009). Necessitamos repensar a responsabilidade científica do investigador em Psicologia e Educação, mas também a sua responsabilidade social (Guzzo, Moreira, \& Mezzalira, 2013; Veiga, 2013). Se a Psicologia e a Educação não enveredarem por um conceito de investigação assente no rigor e na busca do bem para todos, estarão condenadas a não serem "grandes". Para isso, é preciso aceitar fazer muitas pequenas coisas: quem não for capaz de aceitar fazer pequenas coisas jamais verá perante si as coisas grandes. Fazê-las no âmbito da internacionalização do conhecimento pode ser uma boa forma.

\section{Internacionalização}

O conceito de internacionalização da educação superior surge como complexo, com uma diversidade de termos relacionados e várias fases de desenvolvimento. Bartell (2003) conceitualiza a relacionadas com o conhecimento, e define a globalização como uma avançada fase do processo da internacionalização. Morosini (2006), procurando identificar o estado de conhecimento sobre internacionalização universitária e recorrendo a dados de periódicos da Europa e da América do Norte, releva que a internacionalização da educação superior se fortificou, sobretudo a partir da década de 1990, e que, nos dias de hoje, necessita de políticas que freiem a perspetiva mercantilista e que contribuam para a qualidade acadêmica e o bem-estar social.

As estratégias de internacionalização marcam o século XXI e estão voltadas mais para a função de ensino do que para a pesquisa. Nesse período, cresceu o número de produções científicas que discutem as estratégias de internacionalização: nível de ensino, aprendizagens, construção de identidades, adaptação, currículos internacionalizados e desenvolvimento tecnológico para apoio à internacionalização.

Considerando a internacionalização dos currículos, Feitosa (2007), da Universidade de Brasília, examinou o contexto da política educacional brasileira e comparou-o com o contexto de internacionalização da Educação; procedendo a uma análise da formação em Psicologia no Brasil e no cenário de internacionalização. Se o Brasil teve, na década de 1960, um cenário de reforma universitária inspirado nas universidades americanas, tem hoje o cenário de uma reestruturação do ensino superior vindo da Europa, relevando o Processo de Bolonha e a internacionalização da educação. Atualmente, os modelos europeu, português e brasileiro de ensino da Psicologia assemelham-se, parcialmente, quanto à organização e ao objetivo central de formar psicólogos e professores.

Entre os programas de mobilidade internacional, merece referência o programa Erasmus, que já beneficiou mais de dois milhões de jovens estudantes europeus, sendo considerado um dos maiores êxitos da política europeia comum (Santos \& Almeida-Filho, 2012). O Programa de Licenciaturas Internacionais (PLI) incide na formação de professores do ensino básico e secundário, e permite a mobilidade acadêmica de estudantes de universidades brasileiras e universidades portuguesas. 
Importantes são também os estudos que têm surgido e que abordam os problemas psicossociais dos alunos estrangeiros, a fim de se integrarem estratégias de aprendizagem. Hellsten e Prescott (2004) defendem os métodos interativos (ensino baseado na discussão) como superiores aos métodos centrados no professor. São também apontados o ensino e a pesquisa em rede, que, num ensino à distância, possibilitam a desvinculação do contato presencial (Feitosa, 2007).

Entretanto, sem investimento, não pode haver internacionalização. As Ciências Sociais e Humanas (CSH) passaram recentemente a ser financiadas a $15 \%$ do total do financiamento público para a Ciência, e não a 22\%, como até então. Ao diminuir o investimento na ciência, ao recusar emprego a jovens cientistas bem-preparados, está-se a deitar fora a chave do futuro (Fiolhais, 2014). Quais são as consequências disso? Ficamos cientificamente mais pobres, o que significa, cultural e socialmente mais fracos. Os jovens mais capazes, em cuja preparação investimos, estão a sair para outros países (Fiolhais, 2014).

Assim, eu olho o meu país e lembro-me dos versos do poeta Manuel António Pina (2011), quando disse "do que podia ter sido/restam ruínas".

Apesar desses fracassos associados ao ensino superior, as experiências de internacionalização mais evoluídas e politicamente mais significativas podem ser encontradas na Europa e na América Latina. No Brasil, a recente posição da Presidente Dilma de conceder aos Estados Unidos uma posição de preferência no quadro do recém-criado Programa Ciência sem Fronteiras - que visa colocar cem mil estudantes brasileiros no exterior até 2014, em resposta a uma aproximação do Presidente Barack Obama -, não pode deixar a ideia de subvalorização do mundo lusófono.

As experiências de internacionalização universitária, já em prática entre Portugal e Brasil, podem ser estendidas aos restantes países de língua portuguesa. Temos já ligações com esses países, como Angola, Moçambique e Cabo Verde. Duas organizações já existentes têm como missão a internacionalização universitária do mundo lusófono: a Associação de Universidades de Língua
Portuguesa e a Universidade Federal de Integração Internacional da Lusofonia Afro-Brasileira (UNILAB).

A universidade não pode recusar o desafio da internacionalização, com receio de ver comprometida a sua autonomia. De fato, assiste-se ao fortalecer de uma nova dimensão de avaliação das universidades, baseada em índices de internacionalização, como a percentagem de estudantes e de professores estrangeiros. Segundo dados da Direção-Geral de Estatísticas da Educação e Ciência (Portugal, 2013), o número de alunos internacionais em instituições de ensino portuguesas cresceu $60,0 \%$ nos três últimos anos, o que transforma as escolas numa aldeia global, onde coabitam jovens de 174 países, que representam 8,5\% do total.

$\mathrm{Na}$ Universidade de Lisboa, a internacionalização é um dos eixos centrais do seu desenvolvimento e da sua identidade (http://internacional. ulisboa.pt/): a instituição valoriza a pluralidade de áreas do conhecimento e a multiculturalidade, atraindo universitários de todo o mundo pela qualidade do ensino e da investigação que pratica. Distinguem-se a mobilidade internacional de alunos e a de docentes.

Mobilidade internacional de alunos: na Universidade de Lisboa, os alunos de licenciatura, mestrado e doutoramento podem realizar um período de mobilidade, entre 2 e 12 meses, em instituições dos diversos países da Europa. No Programa Erasmus, há acordos bilaterais entre as universidades. O Programa Erasmus Estudos permite a mobilidade, entre um semestre e um ano letivo, em instituições de ensino superior na União Europeia; o programa visa a proporcionar um período de estudos, com pleno reconhecimento acadêmico, numa universidade sediada num país da União Europeia e na Turquia, Noruega, Islândia, Liechtenstein, Croácia ou Macedônia. O Programa Erasmus Estágio possibilita, igualmente, a mobilidade entre 2 e 12 meses, permitindo que estudantes do ensino superior, independentemente do seu grau acadêmico, efetuem um estágio profissional curricular ou extracurricular numa empresa ou universidade num outro país participante do programa.

Mobilidade internacional de docentes: no Programa de Mobilidade Erasmus, a mobilidade de 
pessoal docente para missões de ensino tem por objetivo: a) estimular as instituições de ensino superior a alargar e enriquecer o âmbito e os conteúdos dos cursos que oferecem; b) promover o intercâmbio de saber especializado e da experiência relativamente a métodos pedagógicos, e c) criar elos entre instituições de ensino superior e empresas. A mobilidade docente deverá ter uma duração mínima de dois dias (o requisito mínimo para uma missão de ensino é de oito horas de ensino) e máxima de dois meses. Há uma lista de universidades para mobilidade, renovável anualmente. Professores interessados em fazer um período de mobilidade no Instituto de Educação da Universidade de Lisboa (IEUL) podem apresentar, em qualquer altura do ano, uma candidatura ao programa pós-doutoramento, enviando curriculum vitae, carta com indicação da área de investigação e ensino, e carta convite assinada por um professor do IEUL (informações em http://www. ie.ulisboa.pt/portal/).

Assumida nos moldes que cada universidade define, na prossecução de objetivos que a ela compete estabelecer, a internacionalização será um fator que garante e procura a diversidade do sistema. E é aqui que chegamos à importância da cooperação transnacional, através de acordos bilaterais entre Portugal e Brasil.

\section{Convênios FCT/CAPES}

A Fundação para a Ciência e Tecnologia (FCT), em Portugal, e a Fundação Coordenação de Aperfeiçoamento do Pessoal de Nível Superior (CAPES), no Brasil, apoiam atividades conjuntas de investigadores no nível de pós-graduação e de aperfeiçoamento de docentes universitários. Nas páginas Web da FCT e da CAPES, na secção Cooperação Transnacional, encontra-se informação de resposta a perguntas como as seguintes: Quais são as candidaturas elegíveis? Como se processa a abertura dos concursos? Qual o processo de submissão de candidaturas? Quais os critérios na avaliação das candidaturas? Como se procede à avaliação das candidaturas? O que é financiado? Quem pode participar? Quais os prazos de execução? O que é esperado, depois de aprovado? Qual é o calendário das 154 atividades?
Desde que cientificamente fundamentados e inseridos nos critérios de elegibilidade, os projetos a serem propostos podem abranger as mais variadas áreas. Na Psicologia e na Educação, o estudo da motivação dos alunos poderá ser o tema de um projeto, para o qual deixo o desafio.

\section{Um projeto centrado na motivação}

Dentro de vários outros possíveis projetos de interesse de Portugal e do Brasil, poderia ser proposto um projeto intitulado "Motivação dos Alunos para o Desempenho Acadêmico" (MADA). Esse projeto foi recentemente estruturado no âmbito da coordenação do Grupo de Investigação Psicologia da Educação da Unidade de Investigação, Desenvolvimento e Formação (UIDEF) do Instituto de Educação da Universidade de Lisboa (IEUL), e tem por objetivo geral realizar pesquisas sobre a motivação, o rendimento e o comportamento escolar dos alunos.

O estudo dos conceitos motivação dos alunos e desempenho acadêmico tem surgido como importante e atual, sobretudo nas teorias cognitivo-sociais, que destacam a escassez de investigações e a necessidade de aprofundamento das existentes. A motivação apresenta-se ligada ao envolvimento dos alunos na escola, conceito transdisciplinar que tem sido apontado como uma via de respostas aos problemas nas escolas dos nossos dias.

Atendendo à natureza do tema a investigar e suas variáveis, este projeto pode organizar-se em 4 dimensões ou temas mais específicos: (1) Antecedentes da motivação dos alunos para o desempenho acadêmico (MADA): fatores sociofamiliares, escolares e pessoais; (2) MADA: conceptualização e avaliação; (3) Consequentes da MADA: rendimento acadêmico, comportamento escolar, absentismo, abandono, e comportamentos de risco; e (4) Promoção da MADA: elaboração e avaliação de programas de intervenção.

Uma boa notícia, quase de última hora, é a seguinte: na lista da SCImago, publicada no início de fevereiro de 2014, a Universidade de Lisboa é a segunda colocada no ranking ibero-americano, que 
mede a produção científica das instituições de ensino superior. É com orgulho que, sendo minha, vejo a Universidade de Lisboa assim colocada: isso nos dá ânimo para "construir pontes", por onde passem intercâmbios de investigação e ensino, e para manter abertas, ao longo de todo o ano, admissões a programas intercalares de doutoramento e a programas de pós-doutoramento - no âmbito de projetos particulares ou institucionais (FCT/CAPES) -, a fim de valorizar a ligação com o Brasil, com a Europa e com a África.

Uma outra boa notícia, esta vinda da Europa, é a implementação de uma linha de financiamento europeia, denominada Horizonte 2020, que vai ser o maior programa de investigação e inovação mundial. A relatora portuguesa do Parlamento Europeu realçou que a dotação do Programa é de 79,4 mil milhões de euros para o período 2014/2020, conforme pode ser consultado (Almeida, 2013).

Do que foi dito, que ideias-chave poderão agora ser relevadas, sabendo nós que a ciência não tem chaves-mestras que abram todas as portas dos complexos problemas psicológicos e sociais?

\section{Considerações Finais}

Procurou-se trazer aqui elementos de reflexão sobre a realidade psicoeducacional ligada ao tema Desafios da internacionalização da investigação e do ensino em Psicologia e Educação: demandas Portugal-Brasil.

Do que foi dito, urge questionar as orientações de natureza política e pragmática que afetam a investigação e os investigadores em Psicologia e Educação, em contexto nacional e internacional, bem como avaliar os problemas próprios da Psicologia e da Educação, suas potencialidades e perspectivas futuras.

Em um artigo tomado como referência, intitulado "Investigação e investigadores em educação: Anotações críticas", Lima (2009) adverte que o conhecimento, como bem público, está em crise. Emergem, em simultâneo, os novos rankings de instituições, nos quais o modelo anglo-americano volta a sobressair. No ranking que incluiu as pri- meiras duzentas melhores universidades do mundo, publicado em 2009 pelo The Times Higher Education, as primeiras vinte universidades eram todas de língua inglesa: treze dos EUA, cinco do Reino Unido, uma da Austrália e uma do Canadá.

Altbach (2002) adverte que as corporações multinacionais e as grandes universidades podem se tornar neocolonialistas, e procurar o domínio não só por razões ideológicas mas também por objetivos comerciais. A internacionalização universitária é definida como o processo que integra uma dimensão intercultural e internacional em objetivos e oferta (Knight, 2004). Da mesma forma, é reforçada a relação entre globalização e internacionalização: a internacionalização está a transformar o mundo da educação superior, e a globalização está a mudar o mundo da internacionalização (Knight, 2004).

As instituições de ensino superior podem estar a afastar-se de um paradigma educativo, uma vez que a comercialização do conhecimento aparece com força. Não surpreende que os conceitos-chave sejam as qualificações, as competências e as habilidades, deixando para trás a educação, a relação humana, a relação de ajuda, a psicologia, e sua vocação para a transformação da vida, individual e coletiva (Lima, 2009; Veiga, 2013).

Não sei se os consensos serão possíveis ou, mesmo, desejáveis, mas a discussão será. Distintas concepções e projetos de Psicologia e Educação são possíveis e, naturalmente, estão já no terreno, com expressões diversas. Dir-se-ia que é preciso cultivar maior rigor, mesmo admitindo que avançamos bastante nas últimas décadas, sendo hoje possível encontrar investigações e trabalhos de grande mérito e qualidade diante dos melhores padrões internacionais. Parece indispensável criar condições para que se abandone uma atitude defensiva, como se a área da Psicologia e da Educação fosse algo frágil, o que é parcialmente verdade, mas pode ser mudado. Pergunta-se: os índices de citação são aplicáveis sem problemas e são adequados ao trabalho investigativo? Os projetos editoriais das unidades de investigação, sobretudo no caso das revistas acadêmicas de circulação internacional, não devem ser especialmente valorizados? 
Se os problemas são muitos, não se deve desprezar as potencialidades da Psicologia e da Educação; de forma simplesmente exemplificativa, especifico: a existência de um número de doutorados, de unidades de investigação, de mestrandos e doutorandos sem precedentes na história; e a existência de uma considerável capacidade de atração de estudantes de pós-graduação e de pós-doutoramento, designadamente portugueses e de países de língua oficial portuguesa, com destaque para o Brasil.

Nesses e noutros aspetos, há que se reconhecer que a área da Psicologia e da Educação nunca antes foi tão forte. De qualquer modo, uma conceção instrumental e estritamente aplicada da Psicologia e Educação, de feição tecnicista e prescritiva, será aquela que menos contribuirá para a consolidação científica do conhecimento psicológico e educacional, para a sua função crítica e para o seu impacto psicossocial.

O que foi dito conduz a um caminho que retoma obstáculos sociopolíticos, que se destacam em seguida.

Elementos sociopolíticos. Começa a sentir-se, em Portugal, que alguns alunos mais carentes estão a abandonar a universidade quando, já na reforma republicana, proclamava-se "que ninguém fique de fora" da escolaridade a que tem direito (Nóvoa, 2001). Embora o Programa das Nações Unidas para o Desenvolvimento (PNUD) mostre que a fome e a pobreza têm diminuído no mundo, estamos a passar por momentos difíceis, em que a injustiça, a iniquidade, o desemprego e a fome fazem parte da realidade de muitas pessoas (Mendes, 2002). Na Europa, Portugal surge como um dos países em que as desigualdades sociais são maiores, apesar de o poder ter sido sempre exercido por dois dos partidos com maior representação social.

Que soluções existem no mundo, dito moderno, para tal estado de coisas que envergonha a humanidade? Embora tenham vindo a aumentar as preocupações da comunidade mundial por esses problemas, não é muito provável que tal situação se altere nos próximos anos. Então, onde está a 156 solução?
As respostas para tais problemas têm de ser encontradas na educação, talvez recorrendo a um dos mais importantes direitos humanos, o direito à indignação, para utilizar as palavras de Hessel (2011), no seu recente e famoso opúsculo intitulado "Indignai-vos". Embora saibamos que muito se tem feito nos últimos anos, reconheça-se por tudo isso o direito à indignaçãa.

O que nos leva aos versos de Hélia Correia (2012), quando, no seu recente livro premiado, intitulado "A Terceira Miséria", diz: "De que armas dispomos / senão destas / que estão dentro do corpo: o pensamento ..., do qual virá um início?".

É isso: precisamos de um início. Precisamos de escolas e de países que, educando, transmitam valores e previsibilidade. Urge passar do desamparo ao amparo, do desânimo ao ânimo, do ilógico ao psicológico, e do monetário ao humanitário. É isso: precisamos de um início.

Sabe-se, pela Ciência e pela História, que quanto mais problemas econômicos e sociais tem um país, mais deverá melhorar a qualidade do ensino e da investigação, pois é daí que pode surgir o impulso necessário a um estado de desenvolvimento superior, com satisfação dos direitos das pessoas, de todos, na escola e na vida (Veiga, García, Neto, \& Almeida, 2009).

Diz-se que o homem vale, sobretudo, pela educação que possui (Veiga, 2012). Frase orientadora desses esparsos pensamentos - que nos foi conduzindo à metáfora da vela que ilumina, mas que, ardendo, consome-se e transubstancia. De fato, homens houve que - grandemente escolarizados, letrados e diplomados -, ficaram na história como ditadores. Assim, à frase O homem vale, sobretudo, pela educação que possui urge acrescentar e que o leva a pensar, sentir e agir, não como ateniense nem grego, mas como um cidadão do mundo.

Perante os horrores daquilo que aconteceu num campo de concentração nazi, o papa João Paulo Il disse um dia: "Onde estavas tu, Deus, quando isto aconteceu?". Faz anos, eu visitei um desses campos e, todo eu tremendo, pensei: os indivíduos que praticaram tais horrores estavam entre os mais 
escolarizados. Como é possível ter grande sabedoria e, simultaneamente, ser monstro, com seguidores terríficos?

O que temos que saber é que nada do que é humano nos pode ser estranho. O que temos que fazer é tomar como azimute a dignidade humana, em tudo o que temos em Psicologia e Educação. Há muito que "fazer", mesmo sabendo que temos muito que esperar, pois, como disse Albert Camus, as grandes ideias vêm mansamente. Pense-se não a partir do econômico, mas a partir do psicológico, das pessoas, do social, do bem-comum.

Do que foi dito - e do meu ponto de vista, sabendo que um ponto de vista não é mais do que a vista através de um ponto -, há que humanizar, há que ligar valores, ensino e investigação, graduação e pós-graduação. Há que promover a combinação de conteúdos e competências, bem como a mobilidade de estudantes, de professores e de psicólogos. É preciso levar a ciência aos cidadãos.

Antes de terminar, permitam-me fazer aqui um apelo: psicólogos, sede, sejamos Psicólogos; professores, sede, sejamos Professores; estudantes, sede, sejamos Estudantes; sociedades, sede Sociais. Leve-se daqui uma ideia de Padre António Vieira: "Nós somos o que fazemos. O que não se faz não existe. Portanto, só existimos nos dias em que fazemos. Nos dias em que não fazemos apenas duramos". Essas palavras conduzem-nos a Mandela, quando diz que "Um santo é um pecador que luta até ao fim" (Moreira, 2013, p.41).

Precisamos pensar criticamente! Pensar criticamente a formação dos psicólogos (Guzzo et al., 2013) e dos professores (Veiga, 2013). E... sonhe-se! Do que pode vir a ser, / aurore / de tudo o bem de todos.

Antes de terminar, vejo a necessidade de construir pontes, entre países, entre Portugal e o Brasil. O mapa é magno, é o mundo, mas há que o fazer, porque quando o homem sonha, a obra nasce, se Deus quiser.

Quando a Ciência e a Educação tiverem evoluído ao ponto de sabermos que nunca mais haverá coisas horrendas como campos de concentração nazis, quando tivermos um "ensino para todos", então atingiremos o estado superior da Educação. Finalmente - e para terminar por aqui -, quando atingirmos o estado superior da Educação, então todas as pessoas, ao acordarem pela manhã, sentirão uma vivência de atração centrípeta para o bem-comum. Enquanto isso não acontecer, continuará a justificar-se a nossa preocupação com a ciência e com a investigação, com a Psicologia e com a Educação.

\section{Referências}

Almeida S. (2013). Horizonte 2020. Newsletter Incentivos: Vida Económica, 106, 5. Recuperado em abril 3, 2014, de http://issuu.com/vidaeconomica/docs/incentivos 20131203

Altbach, P. G. (2001). Why higher education is not a global commodity. Chronicle Review. Retrieved March 3, 2014, from http://chronicle.com/weekly/V47/i35/ 35bo2o01.htm

Bartell, M. (2003). Internationalization of universities: A university culture-based framework. Higher Education, 45, 43-70.

Correia, H. (2012). A terceira miséria. Lisboa: Edição Relógio D’Água.

Estrela, M. T. (2008). As ciências da educação, hoje. In J. M. Sousa (Org.), Actas do IX Congresso da SPCE, Educação para o sucesso: políticas e atores. Funchal: SPCE, 15-35.

Feitosa, M. A. G. (2007). Implicações da internacionalização da educação para a formulação de currículos em psicologia. Temas em Psicologia, 15(1), 91-103.

Fiolhais C. (2014 janeiro 16). Reduzir o investimento na ciência é deitar fora a chave do futuro (entrevista a Filomena Naves). Diário de Notícias, p.27.

Guzzo, R. S. L., Moreira, A. P. G., \& Mezzalira, A. S. C. (2013). Intervenção psicossocial: teoria e prática na inserção do psicólogo em instituições públicas de ensino. In M. H. Bernardo, R. S. L. Guzzo \& V. L. Souza (Orgs.), Psicologia social: perspectivas críticas de atuação e pesquisa (pp.69-89). Campinas: Alínea.

Helisten, M., \& Prescott, A. (2004). Learning at university: The international student experience. International Education Journal, 5(3), 344-351.

Hessel, S. (2011). Indignez-vous. Paris: Indigène Éditions.

Knight, J. (2004). Internationalization remodeled: Definition, approaches, and rationales. Journal of Studies in International Education, 8(1), 5-32.

Lima, L. (2009). Investigação e investigadores em educação: anotações críticas. Sísifo: Revista de Ciências da Educação, 12, 63-72. 
Mendes, V. (2002). Direitos humanos: declarações e convenções internacionais. Lisboa: Vislis Editores.

Moreira, A. M. (2013). Memórias do outono ocidental: um século sem bússola. Coimbra: Almedina.

Morosini, M. C. (2006). Estado do conhecimento sobre internacionalização da educação superior: conceitos e práticas. Educar em Revista, 28, 107-124.

Nóvoa, A. (2001). Eu pedagogo me confesso: diálogos com Rui Grácio. Inovação, 14(1-2), 9-33.

Nóvoa, A. S. (2014). Adriano Moreira: memórias do outono ocidental: um século sem bússola. Jornal de Letras, 130. Recuperado abril 2, 2014, de www. jornaldeletras.sapo.pt

Organisation for Economic Co-Operation and Development. (2013). Education at a Glance 2013: OECD Indicators. Retrieved April 3, 2014, from http:// www. oecd-ilibrary.org/education/education-at-aglance-2013_eag-2013-en

Pacheco, J. (2010). Ciências da educação e investigação: o pesadelo que é o presente. Sísifo: Revista de Ciências da Educação, 12, 5-18.

Pina, M. A. (2011). Como se desenha uma casa. Lisboa: Assírio \& Alvim.

Portugal. Ministério da Educação e Ciência. (2013). Principais resultados do Inquérito ao Registo de Alunos Inscritos e Diplomados do Ensino Superior (RAIDES). Recuperado em abril 3, 2014, de http://www.dgeec.
mec.pt/np4/EstatVagasInsc/\%7B \$clientServlet Path \%7D/?newsld=120\&fileName=Result_Mobilidade_ RAIDE12.pdf

Santos, F. S., \& Almeida-Filho, N. A. (2012). A quarta missão da universidade. internacionalização universitária na sociedade do conhecimento. Coimbra: Universidade de Coimbra.

Veiga, F. H. (2006). Vapor de pedra. Lisboa: Universitária Editora.

Veiga, F. H. (2012). Direitos dos jovens alunos: elementos na reforma republicana do ensino e na escola atual (pp.99-110). In A. Adão, C. M. Silva \& J. Pintassilgo (Org.), O homem vale, sobretudo, pela educação que possui: revisitando a primeira reforma republicana do ensino infantil, primário e normal. Lisboa: Universidade de Lisboa.

Veiga, F. H. (Coord.). (2013). Psicologia da educação: teoria, investigação e aplicação: envolvimento dos alunos na escola. Lisboa: Climepsi Editora.

Veiga, F. H., García, F., Neto, F., \& Almeida, L. (2009). The differentiation and promotion of students' rights in Portugal. School Psychology International, 30(4), 421-436.

Recebido em: 7/3/2014

Aprovado em: 20/3/2014 